\title{
Fluid Balance in Sepsis: Have We Resolved the Controversies?
}

\author{
Igor Klepikov* \\ Pediatric Surgeon, USA \\ *Corresponding Author: Igor Klepikov, Pediatric Surgeon, Renton, WA, USA.
}

Received: October 14, 2019; Published: October 23, 2019

DOI: 10.31080/ASMS.2019.03.0449

This article is devoted to a very complex and urgent problemthe treatment of patients with septic shock. The authors conducted a thorough and time-consuming review based on the analysis of the most extensive and fundamental research in this field of medicine. The materials of the review did not allow the authors to come to any definite conclusion at the end, despite the maximum possible analysis of the published materials, since the articles presented in the list of references and formed the basis of this review have similar difficulties. The reasons for this uncertainty and incompleteness, from my point of view, lie in the shortcomings of ideology and ideas about the mechanisms of this dangerous pathology.

The main purpose of the study is presented in the form of a collective concept of "septic shock" without the isolation of separate groups of patients depending on the nosologically cause that caused this complication. This fact indicates that shock researchers have lost interest in its source and ceased to attach importance to methods of influence on the root cause of the disease. Starting with the description of shock in General and septic shock in particular, serious importance was attached to the methods of influence on the primary focus of the disease. From this point of view, it is even theoretically difficult to predict therapeutic success in the fight against shock without suppressing the sociogenic role of the underlying cause of the disease.

Here, in this connection, I would like to draw your attention to only one group of patients, which, not only and not so much from my point of view, as by virtue of biological norms and laws, requires completely different assessments and therapeutic approaches. We are talking about the so-called septic shock in patients with acute pneumonia (AP). Why "so-called" can be understood based on known, proven and indisputable biological norms and laws, while convincing arguments in favor of only the septic nature of shock in such patients do not.

First, septic shock in General is a severe complication of inflammatory diseases in most of its nonspecific etiology.

Secondly, it is necessary to remember that the basis of inflammatory tissue transformation is a vascular reaction, with a standard change of its stages. The reaction of the body and therefore the rate of development of inflammatory transformation is an individual characteristic that ranges from relatively smooth development to lightning-fast character.

Thirdly, in the long list of acute nonspecific inflammatory diseases, AP is the only process occurring in the vessels of the small, not the large circle of blood circulation.

Fourthly, the fundamental differences between systemic and pulmonary circulation, as well as their inverse interdependence, have long been studied, established and well known. The need for a special approach in AP to the choice of treatment methods will become an obvious necessity if we once again evaluate and weigh the features of blood circulation and its regulation in the small circle [1-7].

Fifth, try to find out the statistics of the causative agents of the so-called septic shock in AP. Among the large number of publications on this topic, I have not been able to find an exhaustive answer to this question. Avoiding discussion of the results on the etiology of septic shock, the authors nevertheless invariably emphasize the important role of antibacterial therapy in the treatment of these patients, and one of the main reasons for failures in treatment is usually considered to be the shortcomings of Express microbiologi- 
cal diagnosis. Paradox? Undoubtedly, since positive bacteriological blood tests in patients with AP are recorded only in $10-12 \%$, including both observations of shock and bacteremia and sepsis combined [8-11]. These incomplete results look very strange also because the concrete form of shock without cardinal confirmation of its nature is discussed.

From my point of view, such dominant misconceptions arose and strengthened as a result of blind faith in the exclusivity of antibiotics and exaggeration of the role of symbionts as a separate and independent cause of the disease.

In the analyzed literature review, as well as in the publications that form its basis, it is impossible to determine the proportion of patients with shock in AP, but indirect details of the description of the material suggest that such patients are represented in these data. In this connection, I would like to draw the attention of readers to one very noticeable and significant detail. Attempts to increase the volume and speed of intravenous injections in patients with shock contributed to the deterioration of patients and increased mortality. Such consequences of increased blood flow in the zone of the small circle of blood circulation are especially and primarily characteristic of the initial stage of aggressive forms of AP [12].

In this comment, the author wanted to draw the attention of readers to only one group of shock patients, which today is declaratively, without convincing evidence, defined as septic. A different view of the causes of this diagnosis allowed the author of these lines more than thirty years ago not only to achieve excellent results in the treatment of the most severe group of patients with aggressive forms of AP, many of whom entered the clinic in a state of shock, but also to prove the possibility of guaranteed prevention of complications of the disease in the treatment process [13].

The proposed comment can be left without due attention as a separate opinion without subsequent correction of theoretical ideas and practical efforts, but this will not help to avoid the influence of biological canons in the dynamics of the disease. These biological laws and norms have been, are, and will operate independently of our perception of them [14-18]. The validity of certain trends in medical science and practice is determined not by their spread and dominance in the public consciousness, but by specific consequences and results. Therefore, the departure from the fundamental foundations of the studied phenomenon should be considered as a narrowing of views on the causes of the problem and unintentional self-deception.

\section{Bibliography}

1. Igor Klepikov. "What are the specifics of modern treatment of acute pneumonia?". Chinese Journal of Medical Research 2.1 (2019): 01-03.

2. Igor Klepikov. "First Aid for Aggressive Forms of Acute Pneumonia". EC Pulmonology and Respiratory Medicine 7.2 (2018): 34-37.

3. Klepikov I. "The Meaning of Pulmonary Reflexes in the Pathogenesis of Acute Pneumonia". Internal Medicine 7 (2017): 232.

4. Klepikov I. "Shock in Acute Pneumonia and its Mechanism". EC Emergency Medicine and Critical Care 2.2 (2018): 52-53.

5. Igor Klepikov. "The Role of Cardiovascular Disorders in the Pathogenesis of Acute Pneumonia". Journal of Cardiology and Cardiovascular Therapy 4.1 (2017).

6. Igor Klepikov. "Cupping therapy in the 21st century? - Why not!?". Journal of General and Emergency Medicine 2.5 (2017).

7. Klepikov I. "Acute Pneumonia is More Cardiovascular than Respiratory Disaster". The Journal of Emergency Medicine 1.1 (2018): 105.

8. AJ Morgan and AJ Glossop. "Severe community-acquired pneumonia”. BJA Education 16.5 (2016): 167-172.

9. Sanjay Sethi. "Community-Acquired Pneumonia”. Merck Manual, professional version.

10. GW Waterer., et al. "Septic Shock and Respiratory Failure in Community-acquired Pneumonia Have Different TNF Polymorphism Associations". American Journal of Respiratory and Critical Care Medicine 163.7 (2001): 1599-1604.

11. Igor Klepikov. "Mortality in Acute Pneumonia: Fatal Inevitlitabiy?". EC Anesthesia 5.4 (2019): 106-109.

12. Igor Klepikov. "The Effect of Intravenous Infusion on the Dynamics of Acute Pneumonia". EC Pulmonology and Respiratory Medicine 4.1 (2017): 15-20.

13. Klepikov I. "Acute pneumonia and its purulent and destructive complications in children in the midst of a major industrial centre of Western Siberia". Dissertation for the degree of doctor of medical science". Leningrad (1989). 
14. I Klepikov. "Why does acute pneumonia remain a medical problem in the 21st century?". Acta Sientific Medical Siences 2.8 (2018): 51-54.

15. Klepikov I. "The Origins of the Modern Concept of Acute Pneumonia". Journal of Pediatrics Research and Therapeutics (2018): 101.

16. Igor Klepikov. "Why the Modern Idea of Acute Pneumonia are contradicted by Scientific Facts?". EC Aneasthesia 5.2 (2019): 37-39.

17. I Klepikov. "Acute Pneumonia: Biological Rules and Laws require Attention and Respect". Journal of Respiratory Diseases 1.1 (2019): 25-29.

18. Klepikov Igor. "Do you really want to improve the results of treatment for acute pneumonia?". Journal of Clinical Intensive Care and Medicine 4 (2019): 023-027.

Volume 3 Issue 11 November 2019

(C) All rights are reserved by Igor Klepikov. 